\title{
Масс-спектрометрия
}

\section{для исследования коррозионных процессов на поверхностях конструкционных материалов}

\author{
А. К.Буряк, Д.Х.Н., Н. П. Платонова, К.Х.Н., \\ И.С. Пыцкий, К. Х.Н., А. В.Ульянов, К.Х.Н. \\ Институт физической химии и электрохимии \\ имени А. Н. Фрумкина РАН, Москва \\ akburyak@mail.ru
}

УДК 544.08544.7548.3543.08

\begin{abstract}
Для исследования продуктов коррозии на поверхности конструкционных материалов предложен комплекс методов, состоящий из термодесорбционной масс-спектрометрии, хромато-масс-спектрометрии, газовой хроматографии - масс-спектрометрии, высокоэффективной жидкостной хроматографии - масс-спектрометрии и активированной матрицей / поверхностью лазерной десорбцией / ионизацией. С помощью выбранных методов можно одновременно анализировать все классы органических и неорганических соединений в широком диапазоне их молекулярных масс на поверхностях разного типа. На примере сплавов АМг-6 и Ад-0, контактировавших с коррозионно-активными компонентами ракетного топлива, отработана методика и показаны преимущества и эффективность совместного использования комплекса методов.
\end{abstract}

\section{ВВЕДЕНИЕ}

Совершенствование современных и развитие новых физикохимических методов позволяют широко их использовать при исследованиях химии поверхности, в том числе для предсказания стабильности и коррозионной стойкости конструкционных материалов под воздействием коррозионно активных сред [1-3].

Исследование коррозии необходимо в первую очередь для прогнозирования сроков развития этого процесса. Общепринятые подходы основываются на накоплении данных о результатах испытаний образцов с целью построения зависимости стойкости материала от времени [4].

Альтернативный способ состоит в изучении закономерностей протекания приводящих к коррозии поверхностных реакций и использовании информации о кинетических характеристиках для прогнозирования стойкости материалов. Для этого требуется детальное изучение механизмов реакций и идентификация продуктов, обычно лабильных и присутствующих в низких концентрациях [5-7]. Перспективными и наиболее информативными среди физико-химических методов анализа сегодня являются хроматография и массспектрометрия [8].
Для исследования продуктов коррозии предлагается набор методов: термодесорбционная масс-спектрометрия (ТДМС), хромато-масс-спектрометрия (ХМС), газовая хроматография масс-спектрометрия (ГХ-МС), высокоэффективная жидкостная хроматография-масс-спектрометрия (ВЭЖХ-МС) и активированная матрицей/поверхностью лазерная десорбция/ионизация (МАЛДИ/ПАЛДИ). Сочетание хроматографии и массспектрометрии позволяет совместить процессы разделения и идентификации компонентов сложных смесей. С помощью выбранных методов можно исследовать поверхности разного типа и одновременно анализировать органические и неорганические соединения всех классов в широком диапазоне молекулярных масс. Отработана методика совместного использования результатов и показаны преимущества, возникающие при комплексном использовании рассмотренных методов.

Настоящее исследование посвящено изучению коррозионных процессов, протекающих на поверхности конструкционных материалов при длительном контакте с компонентами ракетного топлива. Полученные результаты будут использованы для оценки влияния протекающих коррозионных процессов на герметичность и прочность изделий и определения сроков эксплуатации изделий. Изучены реальные образцы, 
длительное время подвергавшиеся воздействию коррозионноактивных компонентов ракетного топлива.

\section{ОБЪЕКТЫ И МЕТОДЫ ИССЛЕДОВАНИЯ}

В качестве объектов исследования выбраны образцы алюминия (Ад-0), сплава алюминия и магния (АМг-6), длительное время контактировавшие с компонентами ракетного топлива (КРТ) - несимметричным диметилгидразином (НДМг) и тетраоксидом азота (АТ). Такие компоненты и продукты их трансформации могут вызывать развитие различных типов коррозии [8], в том числе и питтинговой, которая особо опасна для резервуаров хранения ракетного топлива.

Газовая хроматография - масс-спектрометрия (ГХ-МС) В работе использовали хромато-масс-спектрометр JMS-D300, в котором хроматограф HP 5890 присоединен к масс-спектрометру с помощью струйного сепаратора. Хроматографическое разделение проводили на кварцевой капиллярной колонке 30 м × 0,5 мм со слабополярной жидкой неподвижной фазой ZB-5. Для хроматографического разделения подобрали следующий режим: температура инжектора $280{ }^{\circ} \mathrm{C}$, скорость газа-носителя гелия 5 мл / мин, сброс 1:10. Температуру изменяли по следующей программе: $30^{\circ} \mathrm{C}-4$ мин изотерма $-6^{\circ} /$ мин $-300^{\circ} \mathrm{C}-$ 5 мин изотерма.

Условия масс-спектрометрического детектирования: температура источника ионов 150 $\mathrm{C}$, энергия ионизирующих электронов 70 эВ, ускоряющее напряжение 3 кВ, диапазон массовых чисел от 40 до $450 \mathrm{~m} / \mathrm{z}$. Идентификацию проводили с помощью программы поиска в библиотеке, содержащей 270 тысяч масс-спектров органических соединений [9], и на основании расшифровки масс-спектров, опираясь на основные закономерности фрагментации органических соединений под электронным ударом [10, 11].

Получали хроматограммы по полному ионному току (ПИТ), а для детального анализа снимали масс-хроматограммы по отдельным ионам, характерным для исследуемых молекул. Внутренние стандарты для количественного анализа тетрахлорбензол (CAS95-94-3, ос.4., Acros Organics) и/ или дейтеронафталин (CAS214-552-7, ос.4., Acros Organics).

Пробоподготовка заключалась в обмывании образца растворителем и упаривании полученных смывов. На внутреннюю поверхность, контактировавшую с КРТ, наливали ацетон так, чтобы он покрывал большую часть поверхности, но не переливался через края образца. Выдерживали 30-60 с при периодическом перемешивании иглой шприца. Затем через воронку полученный смыв сливали во флакон. Процедуру повторяли еще 2-3 раза, сливая каждый раз смывы в один и тот же флакон. Жидкость из сосуда упаривали при комнатной температуре на воздухе, потом добавляли внутренний стандарт и использовали для хромато-массспектрометрического исследования.

\section{Термодесорбционная масс-спектрометрия}

Измерения проводили на масс-спектрометре JMS-D300 с термодесорбционной приставкой. Образец помещали в кварцевый капилляр и нагревали со скоростью $20^{\circ} \mathrm{C}$ в мин в интервале от 30 до 400-500 ․ Масс-спектрометрические условия: температура источника ионов $150^{\circ} \mathrm{C}$, энергия ионизирующих электронов 70 эВ, ускоряющее напряжение 3 кВ, диапазон массовых чисел от 40 до $450 \mathrm{~m} / \mathrm{z}$. Продукты термодесорбции из капилляра поступали непосредственно в ионизационную камеру. Такой метод позволяет определять присутствующие на поверхности и в объеме материала соединения, которые выделяются (десорбируются) в газовую фазу при нагреве образца. Однако, для того чтобы разделить объемные и поверхностные продукты десорбции, необходимо провести специальную пробоподготовку - отобрать послойные соскобы с поверхности. С поверхности образцов АМг-б и Ад-О снимали слои материала толщиной 10 мкм до глубины 50 мкм, толщину отбираемого слоя контролировали микрометром.

\section{Масс-спектрометрия с матрично/поверхностно-} активированной лазерной ионизацией / десорбцией Масс-спектрометрические исследования проводили с источником на основе активированной поверхностью и матрицей лазерной десорбцией / ионизацией Bruker Daltonics Ultraflex II (Bruker, Германия), оборудованным азотным лазером с длиной волны излучения 337,1 нм. В качестве инертной поверхности использовали стандартные мишени из нержавеющей стали для нанесения образцов с 384 лунками (Bruker, Германия). Эксперименты проводили в режимах регистрации как положительных, так и отрицательных ионов в следующих условиях (положительные/отрицательные):

- напряжение на выталкивающем электроде, кВ - 25/20;

- д досскоряющее напряжение, кB-20/17,45;

- напряжение на фокусирующей системе, кB-10,50/7,50;

- тормозящее напряжение на ионном зеркале, кВ 26,30/21;

- отражающее напряжение на ионном зеркале, кВ-14,10/11.

Для получения наиболее информативных масс-спектров использовали режим работы лазера: 50 выстрелов с частотой 20 Гц; энергия лазерного импульса составляла 90-100 мкДж.

С поверхности материала проводили смыв ацетоном: 2 мл на 30 см² площади. Полученный экстракт упаривали до 0,5 мл. Каплю полученного экстракта наносили на мишень, дожидались, пока растворитель испарится, после чего добавляли каплю раствора матрицы (2,5-дигидроксибензойной кислоты или аналога) в ацетоне. Анализ проводили после того, как растворитель матрицы испарялся.

Для определения соединений, присутствующих на поверхности, и исследования морфологии поверхности методом МАЛДИ/ПАЛДИ на исследуемые образцы наносили растворы стандартов: йодид калия (ос.ч., "Югреактив") и бромид серебра (х.ч., ГК «Аналитика»). 
Высокоэффективная жидкостная хроматография с масс-спектрометрическим детектированием и электрораспылительной ионизацией

Исследования проводили на жидкостном хроматографе Agilent 1260 серии Infinity (Agilent Technologies, США) с градиентным насосом Quaternary Pump 1260, массспектрометрическим детектором высокого разрешения Maxis Impact (Bruker, Германия) с квадрупольным и времяпролетным масс-анализаторами. Метод ионизации: электрораспыление, программное обеспечение Bruker Compass Data Analysis 4.2. Хроматографическое разделение проводили на колонке Zorbax SB-C18150 × 2,1 мм; 3,5 мкм, (Agilent, США). Градиент: 70\% $\mathrm{H}_{2} \mathrm{O}-30 \% \mathrm{MeCN}$, в течение 20 мин последовательно до 30\% $\mathrm{H}_{2} \mathrm{O}-70 \% \mathrm{MeCN}$, далее в течение 15 мин до 100\% MeCN, после чего 5 мин 100\% MeCN. Расход подвижной фазы 1 мл/мин.

Диапазон масс от 50 до 3000 Да (в режиме регистрации положительных ионов), напряжение на капилляре составляло 4,5 кВ. Масс-спектры вторичных ионов регистрировали с частотой 4 Гц, газ-реактант - $\mathrm{N}_{2}$, энергия соударения - 40 эВ, внутренняя калибровка по формиату натрия (ч.д.а., "Компонент-Реактив»). Точность определения масс составляла 0,001 Да. С поверхности материала проводили смыв ацетонитрилом или ацетоном: 2 мл на 30 см² площади. Полученный экстракт упаривали до 0,5 мл, вводили в хроматограф и проводили анализ.

\section{РЕЗУЛЬТАТЫ И ОБСУЖДЕНИЕ}

Сравнение предлагаемых масс-спектрометрических методов выполнено по результатам исследований авторов [12-14]. Показано, что каждый способ имеет определенные ограничения, а их совместное применение позволяет охватить как широкий диапазон молекулярных весов, так и химических свойств исследуемых соединений, обеспечив комплексный подход к их идентификации.

Особенно важно интерпретировать результаты исследования на основе комплексного подхода, с учетом результатов, полученных разными методами.

Газовая хроматография - масс-спектрометрия (ГХ-МС) Для определения состава органических соединений на поверхности образцов проведено ГХ-МС исследование смывов с поверхности. На рис. 1 приведена хроматограмма смыва с поверхности образца, контактировавшего с НДМг. Наблюдаемые пики принадлежат кремнийорганическим соединениям, используемым в колонке в качестве неподвижной жидкой фазы (пики с временем выхода 22,2 и 26,2 мин); добавленным стандартам (пики с временем выхода 31,2 и 39,1 мин). Также в смеси в незначительных количествах присутствуют примеси в растворителях, использованных для проведения смывов; фталаты и предельные углеводороды. Присутствие в смывах предельных углеводородов и фталата можно объяснить компонентами смазок и других технологических жидкостей, оказавшихся на поверхности исследуемых образцов.

На ПИТ-хроматограмме не обнаружены пики, соответствующие КРТ и продуктам их трансформации.

На основании ГХ-МС данных можно утверждать, что на поверхности исследованных образцов не содержатся КРТ и продукты трансформации, которые могли бы образоваться в результате взаимодействия поверхности с КРТ, в количестве, превышающем 0,1 мг/ см² $^{2}$.

\section{Термодесорбционное масс-спектрометрическое исследование}

Для обнаружения на поверхности образцов КРТ и продуктов их трансформации и определения глубины проникновения органических загрязнений в материал бака проведено исследование послойных соскобов с поверхности образцов с шагом 10 мкм. Получены термограммы по ПИТ послойных соскобов с образца, контактировавшего с горючим (рис. 2) Изучены масс-спектры, соответствующие максимумам выделения из соскоба. При температуре около $100{ }^{\circ} \mathrm{C}$ десорбируется физически адсорбированная вода. При более высоких температурах наблюдается деструкция и пиролиз высокомолекулярных органических соединений, что видно из масс-спектров (см. рис. 2): при $130^{\circ} \mathrm{C}(4,5$ мин) выделяются в основном ионы $\mathrm{c} \mathrm{m} / \mathrm{z}=57$ Да (это предельные углеводороды), а при $400{ }^{\circ} \mathrm{C}-$ углекислый газ (m/z=44 Да), основной продукт пиролиза. Отсутствуют продукты трансформации топлива и вещества, которые могли образоваться в результате взаимодействия поверхности с горючим. Из рис. 2 видно, что больше всего

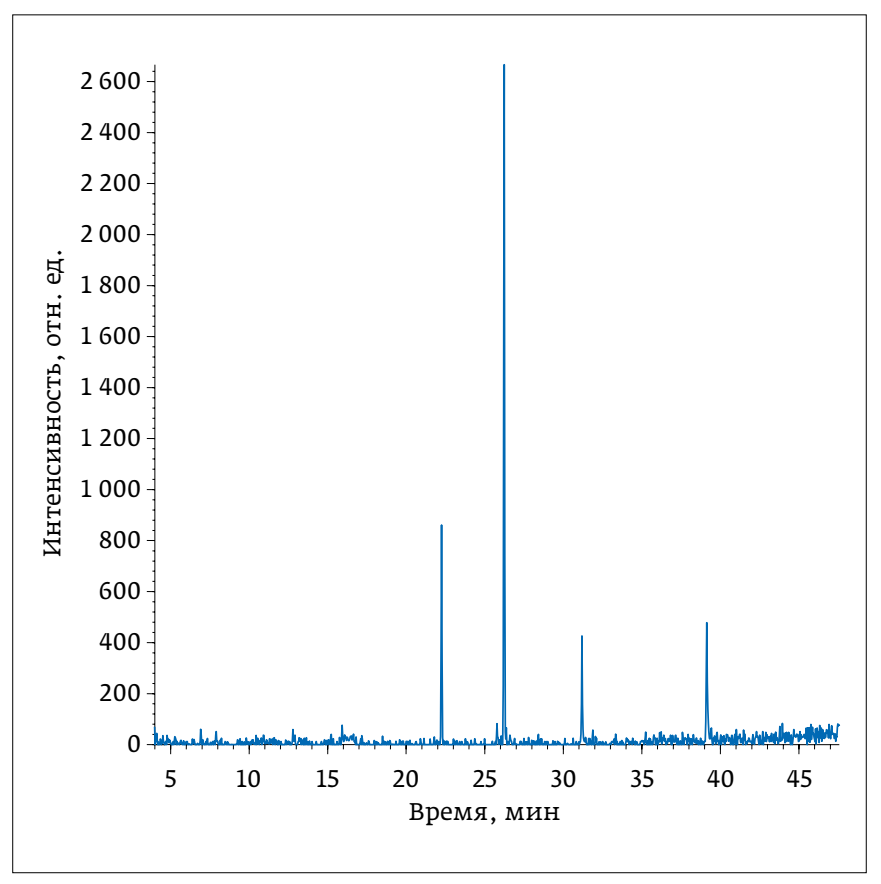

Puc. 1. Хроматограмма по ПИТ смыва с поверхности образиа, контактировавщего с НДМГ 


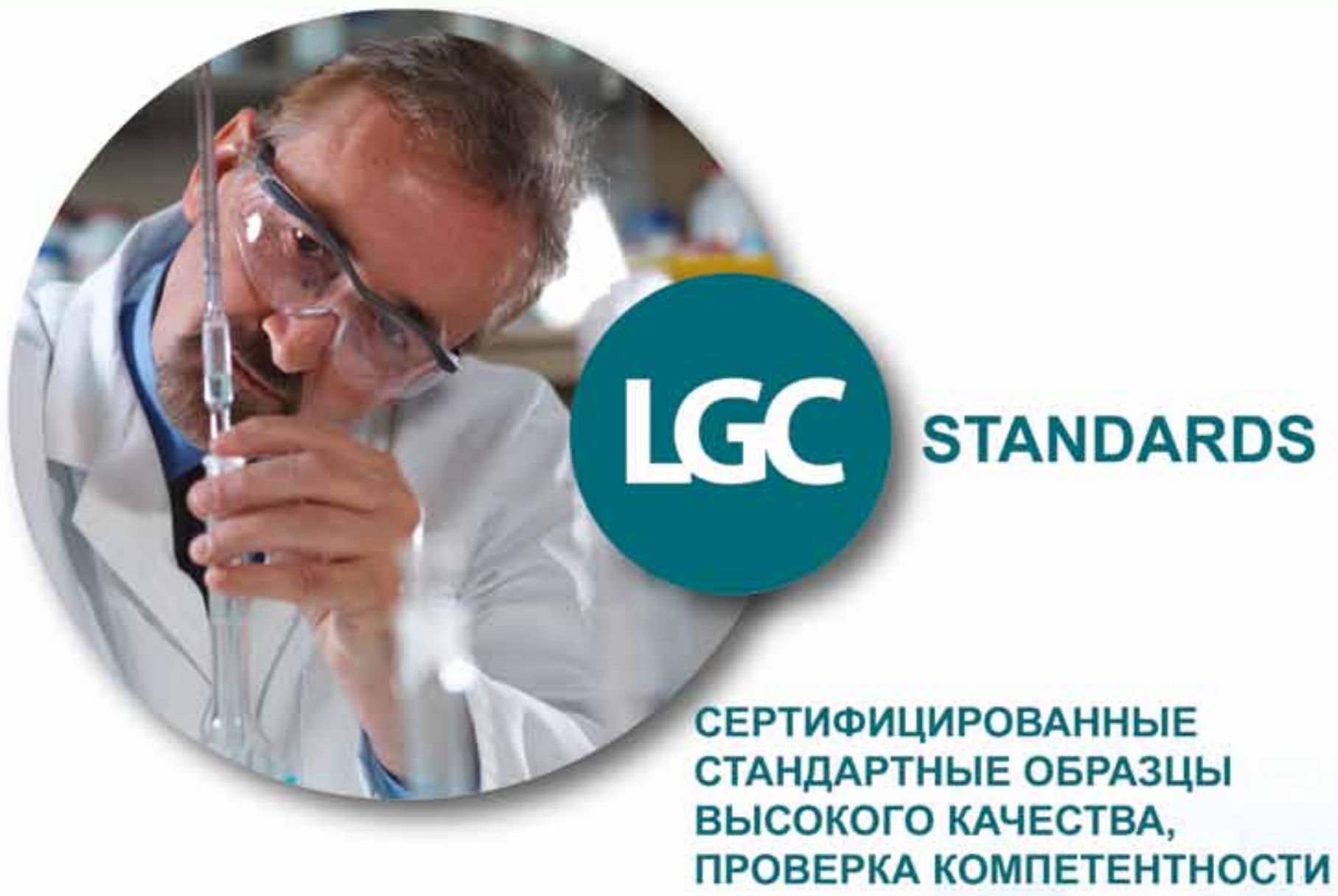

LGC Standards является ведущим поставщиком сертифицированных стандартных образцов, эталонов примесей фармацевтических и наркотических веществ, биологических материалов, а также организатором программ проверки компетентности для фармацевтических, криминалистических, клинических, промышленных лабораторий и проводящих исследования окружающей среды и продуктов питания. Многие наши отделения обладают сертификатом ISO 9001, а наши европейские лаборатории аккредитованы в соответствии с Руководством ISO 34, ISO 17034, ISO/IEC 17043 и ISO/IEC 17025. LGC Standards является частью LGC, выполняющего роль Государственного метрологического института в Великобритании в области химических и биохимических измерений. LGC Standards предлагает техническую поддержку экспертов, а также обслуживание клиентов на местных языках. Мы являемся глобальным лидером продаж, имеющим расширенную логистическую сеть, включающую 30 подразделений и офисов во всем мире. Наше предложение охватывает свыше 100000 продуктов.

\section{НАШИ ПРОДУКТЫ И УСЛУГИ}



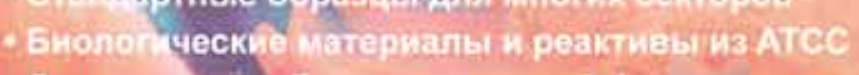

- Gтандартые обравыны примесей фармацевтических веществ

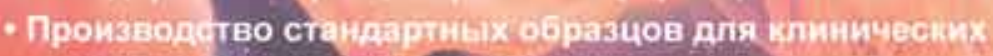

и криминалистически $x$ анапизов

- Растворители высокой чистоты

- Программы проверки компетентносту

197341, Россия, Санкт-Петербург, ул. Парашютная, д.10, корп. 2, оф. 6 Тел.: +7 8127770488

Моб.: +79111493829

E-mail: ru@lgcgroup.com
LGC Standards Sp. z o.o. ul. Ogrodowa 27/29, Kielpin, 05-092 Lomianki, Poland Тел. +48227513140 Факс +48227515845 E-mail pl@igcgroup.com www.Igcstandards.com 
органических загрязнений обнаружено в первом слое. Однако в остальных слоях они также наблюдаются, хотя и в меньших количествах.

На основании полученных данных можно оценить глубину проникновения коррозионного поражения в глубину материала величиной 40-50 мкм.

Для образцов другой серии, длительное время контактировавших с окислителем, обнаружены продукты его трансформации и остатки смазочно-охлаждающих жидкостей не только на поверхности, но и в приповерхностных слоях, в частности на глубине 30-40 мкм. Причинами этого могут быть: слой алюминия, нанесенного в процессе плакировки; изменение структуры

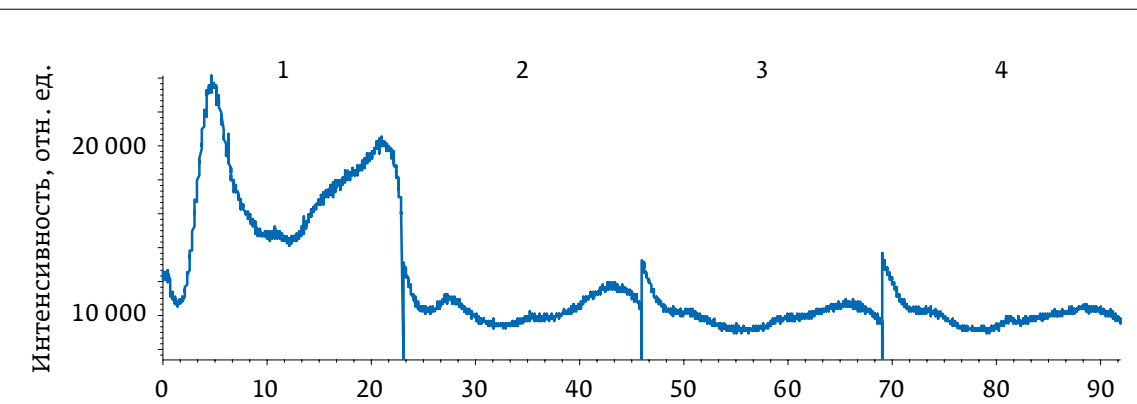

a)

Время, мин
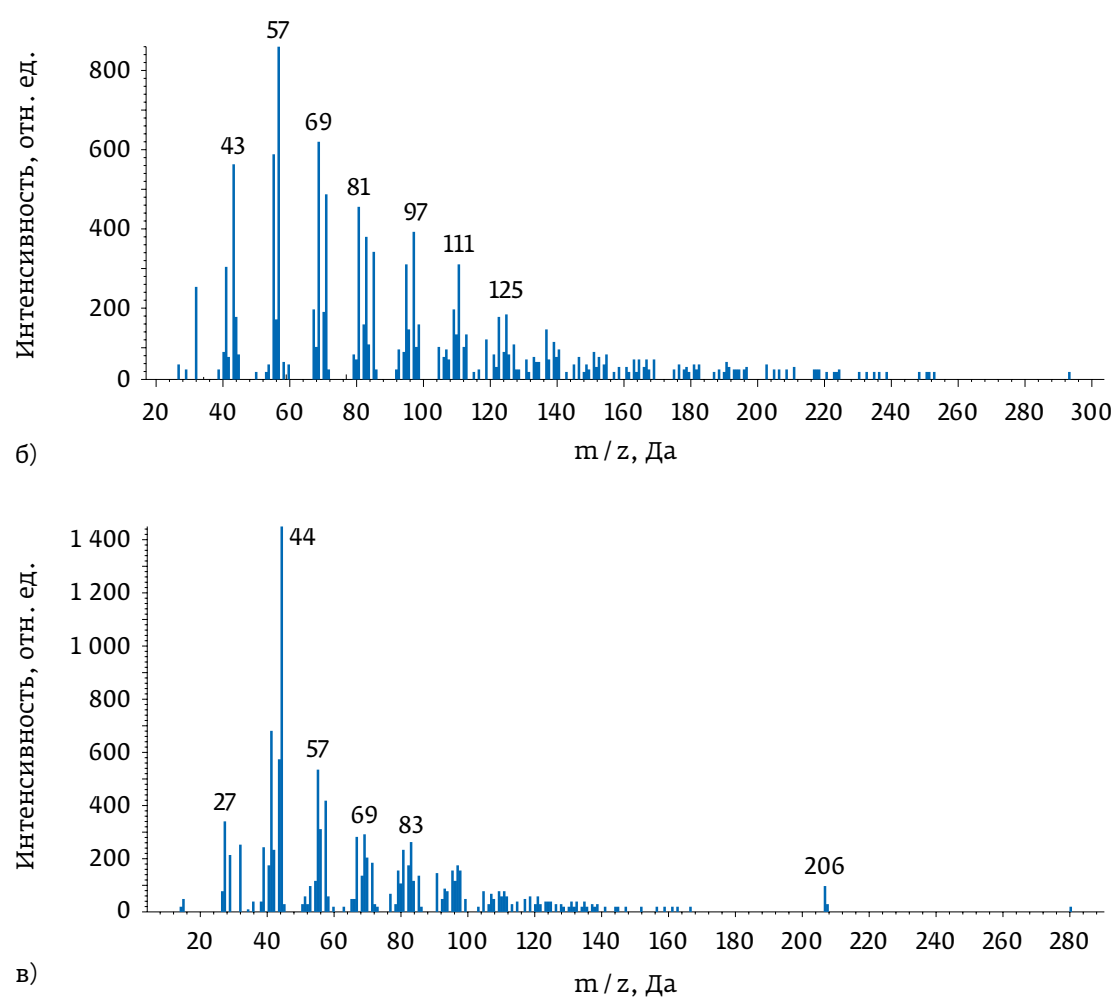

Puс. 2. Термодесорбционные кривые по ПИТ (а) и масс-спектры, соответствующие максимумам выделения при 6-4,5 мин; в - 20,5 мин для послойных соскобов с образца № 4 корпуса бака горючего со стороны, контактировавщей с азотом:

1- 0-10 мкм, 2 - 10-20 мкм, 3 - 20-30 мкм, 4 - 30-40 мкм поверхности при вальцевании материала и дополнительное увеличение поверхностного окисного слоя при очистке поверхности после фрезерования и прокатки. На рис. 3 приведены термодесорбционные кривые для выделения тетраоксида азота и продуктов его трансформации из поверхностных слоев Ад-0, контактировавшего с окислителем. При ТдМс-анализе продукты десорбции попадают в ионизационную камеру источника ионов, где после столкновения с электронами ионизируются. В результате ионизации диоксида азота одним из фрагментных ионов является оксид азота. На рис. 3, помимо наблюдаемых термодесорбционных кривых, приведена расчетная кривая, соответствующая появлению фрагментного иона оксида азота. Она имеет тот же вид, что и кривая выделения диоксида азота. Из рисунка видно, что на поверхности и в приповерхностныхслоях происходит деструкция тетраоксида с образованием различных нитратов и нитритов алюминия, разложение которых при нагревании приводит к образованию наблюдаемых термодесорбционных кривых.

\section{Высокоэффективная} жидкостная хроматография с масс-спектрометрическим детектированием с электораспылительной ионизацией

На полученной хроматограмме (рис. 4) присутствует около 20 пиков, которые можно отнести к нескольким сериям полимер-гомологов. Самые интенсивные сигналы в масс-спектрах компонентов, соответствующих пикам 1-3, имеют m/ z 325, 383 и 441 Да соответственно, так что разности их массовых чисел составляют 58 Да. Далее на хроматограмме наблюдаются пики (4, 8-12, 14, 17), в массспектрах которых наиболее интенсивные сигналы имеют другие массы (516, 574, 632, 690, 748, 806, 864, 922 Да соответственно), однако их разности по-прежнему составляют 58 Да. Важно отметить, что для одних и тех же соединений в масс-спектрах наблюдаются сигналы, как первой, так и второй последовательностей. Установлено, что наиболее интенсивные сигналы в массспектрах первой последовательности соединений соответствуют однозарядным ионам типа [M+H] ${ }^{+}$, в то время как наиболее интенсивные пики из второй последовательности соответствуют 


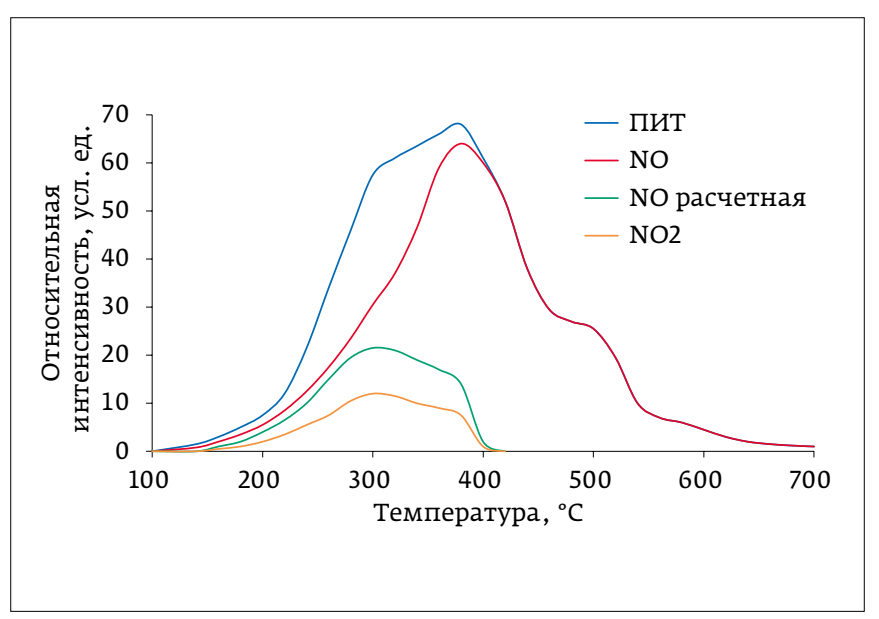

Puс. 3. Термодесорбционные кривые выделения тетраоксида азота и продуктов его трансформации с поверхности АМг-6

аддуктам с ионом аммония: [M+NH4]+. Для более удерживаемых компонентов (пики 19, 21, 24 на хроматограмме рис. 4) в масс-спектрах обнаружены интенсивные пики двухзарядных ионов ( $\mathrm{m} / \mathrm{z}$ 491, 520 и 549 Да соответственно), разности в массовых числах различных соединений составляют 29=58/2 Да. Эти пики соответствуют двухзарядным ионам типа $[\mathrm{M}+\mathrm{H}+\mathrm{NH} 4]^{2+}$, в то время как для наиболее удерживаемых компонентов (пики 26, 28, 30, 32-34) самые интенсивные сигналы принадлежат двухзарядным ионам $[\mathrm{M}+2 \mathrm{NH} 4]^{2+}(\mathrm{m} / \mathrm{z} 586,615,644$, 673, 702, 731 Да).

Хроматографические пики с номерами 5, 13, 18, 20, 22, 23, 25, 31, 35 соответствуют фталатам, алкилсебацинатам и крезилфосфатам. Все эти вещества входят в состав смазочно-охлаждающих жидкостей, применяемых на стадиях производства и эксплуатации изделий.

\section{Исследование методом масс-спектрометрии} с матрично-активированной лазерной

\section{ионизацией / десорбцией}

При регистрации положительных ионов получен масс-спектр, в котором обнаружены пики соединений с m/z 773, 869, 927, 985, $1043,1101,1159,1217,1275$ Да ( $\Delta=58)$. По-видимому, эти пики соответствуют квазимолекулярным ионам гомологов соединений, образующихся при контакте ацетона с образцом, поскольку таких соединений не образуется при смывах ацетонитрилом. Так как разница молекулярных масс указанных соединений постоянна, можно предположить, что они представляют собой олигомеры с единичным звеном, имеющим массу 58 Да, например, ацетон. Такие олигомеры образуются при кислотной или щелочной полимеризации ацетона, вызываемой, в данном случае, остатками продуктов трансформации КРТ. Важное преимущество методов МАЛДИ/ПАЛДИ - возможность регистрирации одновременно органических и неорганических соединений. Результаты подобного исследования приведены на рис. 5 и в табл. 1.

Обнаружен широкий набор органических и неорганических соединений, представляющих собой остатки смазочно-охлаждающих жидкостей, катионов и анионов, занесенных с водой и моющими растворами, а также продукты трансформации горючего. Важно отметить, что пробоподготовка для экспериментов такого рода фактически отсутствует - образец просто помещают в масс-спектрометр с помощью стандартной плашки (рис. 6).

Другое преимущество рассматриваемых методов - возможность визуализации коррозионных поражений с помощью веществ с высоким сечением ионизации.

В методах МАЛДИ и ПАЛДИ существует потенциальная возможность исследования органических соединений при ионизации их на поверхности образца без предварительной

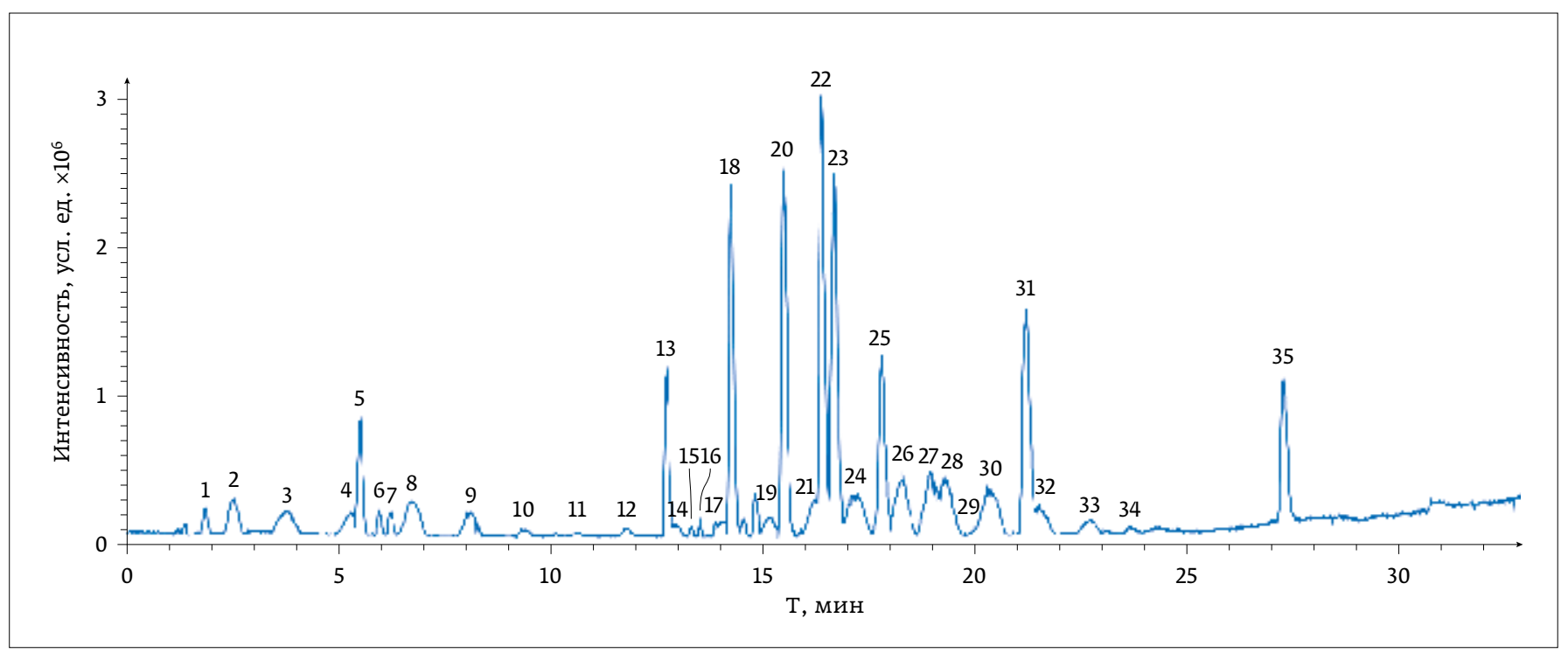

Puc. 4. Хроматограмма смыва с поверхности бака, контактировавщего с горючим 


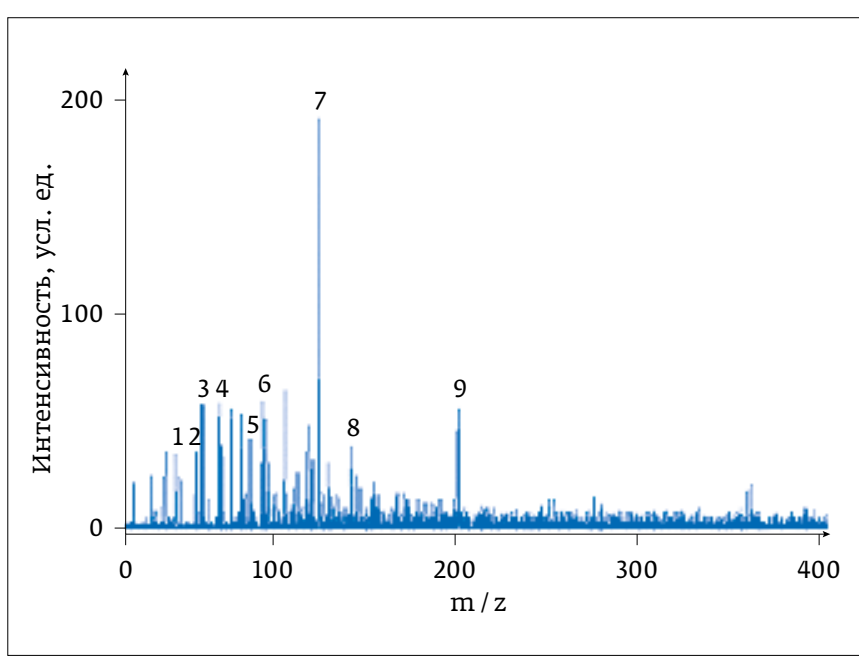

Puc. 5. Масс-спектр МАЛДИ в режиме регистрации отрицательных ионов с поверхности сплава АМг-6 после контакта с тетраоксидом asoma

пробоподготовки. Пластину образца размером $1 \mathrm{~cm}^{2}$ располагают в специально подобранном по глубине отверстии в мишени и помещают в вакуумированную камеру ионизации (см. рис. 6). Лазерным излучением ионизируют соединения на поверхности пробы и регистрируют их массспектры. Этот метод прост в применении и позволяет проводить экспрессный мониторинг поверхностей и оценивать их состояние.

С помощью вещества-маркера с высоким сечением ионизации можно исследовать однородность поверхности топливных баков после их контакта с агрессивной средой КРТ. Подходящими свойствами обладает бромид серебра: при нанесении его раствора на абсолютно гладкую поверхность,

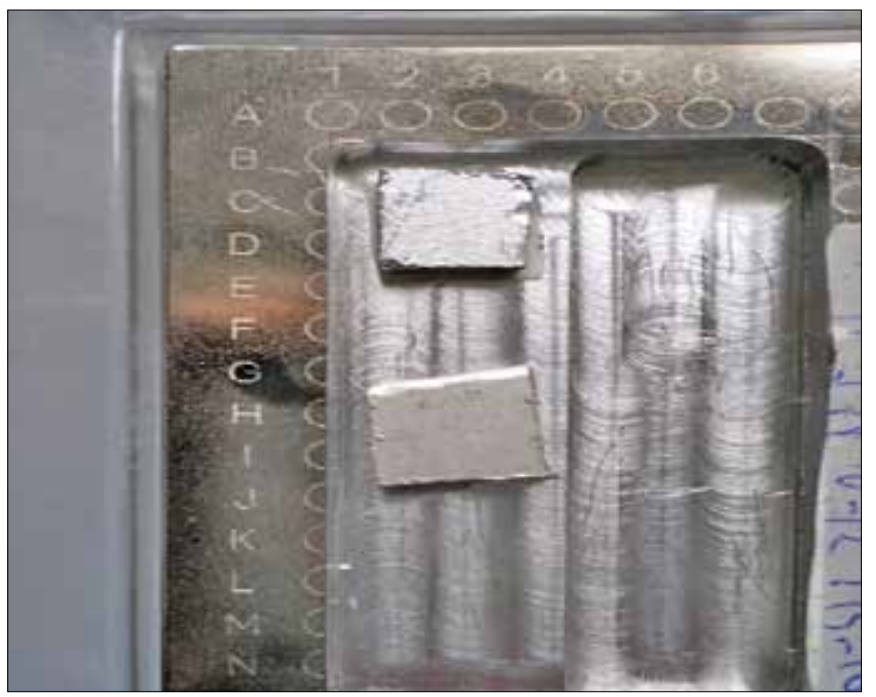

Puc. 6. Образцы топливного бака, подготовленные для массспектрометрического исследования
Табпица 1. Состав соединений, обнаруженных на поверхности сплава АМг-6

\begin{tabular}{|c|c|c|c|}
\hline № пика & $\begin{array}{c}\mathrm{m} / \mathrm{z} \\
\text { Да }\end{array}$ & $\begin{array}{l}\text { Брутто- } \\
\text { формула }\end{array}$ & Предполагаемый ион \\
\hline 1 & 46,0 & $\mathrm{NO}_{2}$ & Нитрит-анион \\
\hline 2 & 59,0 & $\mathrm{C}_{2} \mathrm{H}_{3} \mathrm{O}_{2}$ & Ацетат-анион \\
\hline 3 & 62,0 & $\mathrm{NO}_{3}$ & Нитрат-анион \\
\hline 4 & 73,0 & $\mathrm{C}_{3} \mathrm{H}_{5} \mathrm{O}_{2}$ & Пропионат-анион \\
\hline 5 & 89,0 & $\mathrm{C}_{2} \mathrm{HO}_{4}$ & Оксалат-анион \\
\hline 6 & 97,1 & - & Не идентифицирован \\
\hline 7 & 126,9 & I & $\begin{array}{l}\text { Йодид-анион } \\
\text { (внутренний стандарт) }\end{array}$ \\
\hline 8 & 145,1 & $\mathrm{C}_{6} \mathrm{H}_{9} \mathrm{O}_{4}$ & $\begin{array}{l}\text { Бутил-оксалат-анион } \\
\text { или изомеры }\end{array}$ \\
\hline 9 & 201,1 & $\mathrm{C}_{10} \mathrm{H}_{17} \mathrm{O}_{4}$ & $\begin{array}{l}\text { Октил-оксалат-анион } \\
\text { или изомеры }\end{array}$ \\
\hline
\end{tabular}

он распределяется равномерно и интенсивность массспектров везде одинаковая. Если поверхность неровная, то раствор будет скапливаться в углублениях и для этих участков интенсивность масс-спектров будет выше. При ионизации пятно лазера перемещается по поверхности в двух направлениях.

Так из рис. 7. видно, что распределение бромида серебра по поверхности бака, контактировавшего с окислителем ракетного топлива, крайне неоднородно. На исследуемом образце находятся области, в которых бромид серебра сконцентрировался в значительно большей степени. Скорее всего, появление таких участков объясняется изменением морфологии этой части поверхности.

На рис. 8 приведены диаграммы распределения бромида серебра на поверхности сплава Ад-0, контактировавшего с НДМГ. Наблюдается несколько большее количество областей с повышенной концентрацией вещества по сравнению с рис. 7. Области с высокой концентрацией сильно разбросаны по поверхности, что также говорит об особенностях воздействия агрессивной среды. Таким образом, метод позволяет адекватно оценить однородность и состояние поверхности эксплуатируемого материала. Метод показал свою применимость и адекватность [12-14], а также сходимость результатов с другими независимыми методами [15].

\section{выводы}

На основании полученных результатов можно сделать следующие выводы.

- На поверхностях длительное время контактировавших с КРТ образцов конструкционных материалов АМг-6 и АдО отсутствуют КРТ и продукты их трансформации в количествах, превышающих 0,1 мг/ см². 


\section{СКФ хроматография}

" Разделение в 3-5 раз быстрее, чем в ВЭЖX

= Стоимость расходуемых растворителей в 10-100 раз ниже. чем для аналогичных разделений в ВЭЖX

: Эффективное розделение энантиомеров
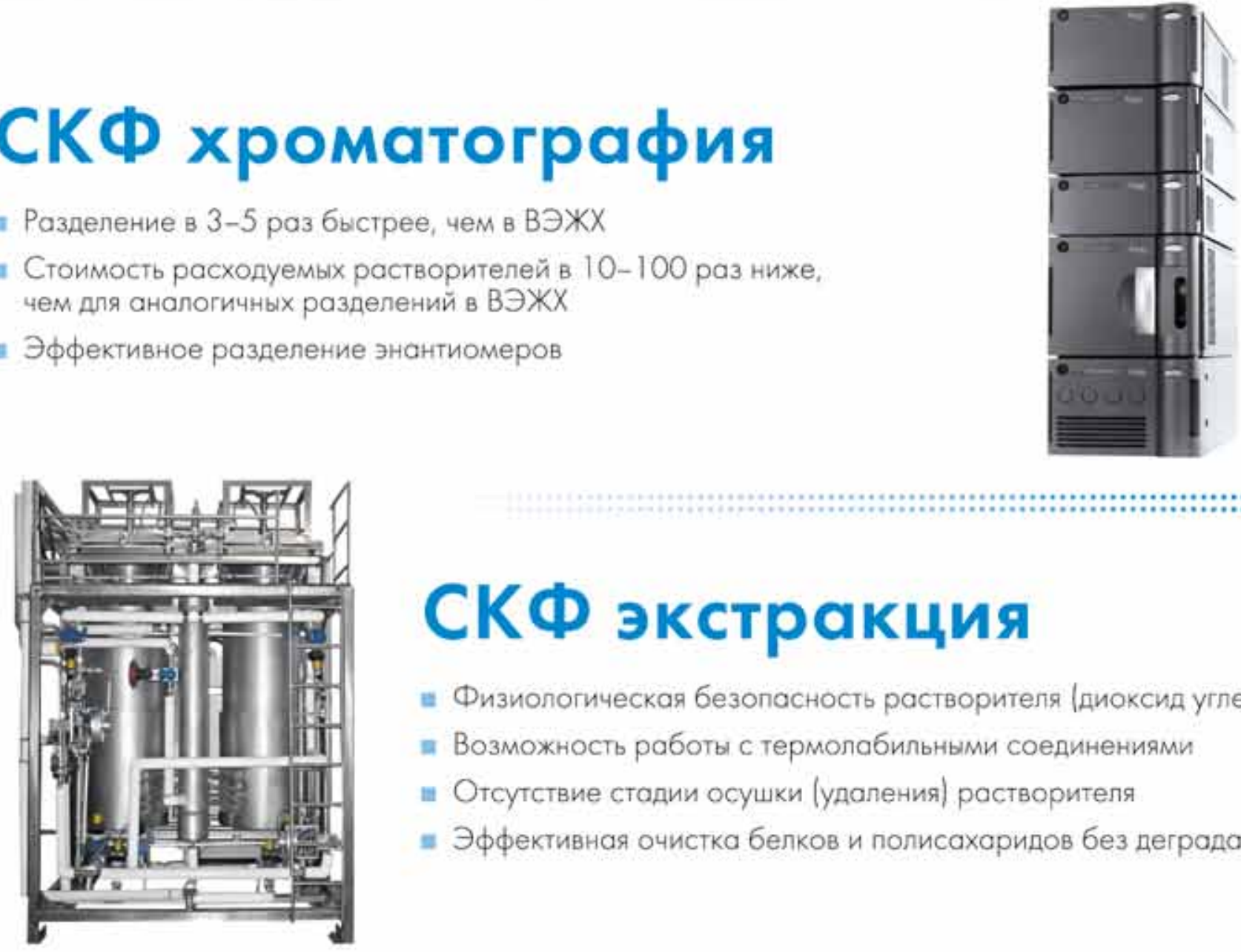

\section{СКФ экстракция}

" Физиологическая безопасность растворителя (диоксид углерода)

" Возможность работы с термолабильными соединениями

in Отсутствие стадии осушки (удаления) ростворителя

= Эффективная очистка белков и полисахаридов без деградации

\section{СКФ микронизация}

n Широкий диапазон возможностей по получению требуемого размера частиц (нано-микро)

" Микронизация термически неустойчивых соединений

= Получение частиц с требуемым распределением по размеру (моно-или полидисперсность порошка)

" Отсутствие стодии сушки

= Возможность получения порошков полимеров, инкапсулированных активным ингредиентам

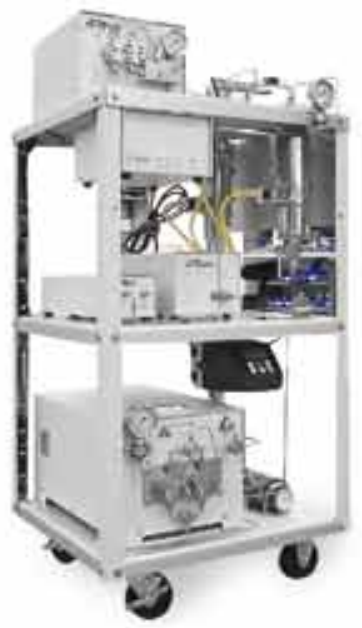

$3 A O$ «ШAГ»

119002, MockBa

Карманицкий пер., 9

Арбат Бизнес Центр, офис 501А Ten.: (495) 956-1309.

Dakc: $(495) 956-1310$

www.schog.ru

info@supercritical.ru
- Полный спектр оборудования для осуществления СКФ технологий: от лабораторных до пипотных и промышленных систем (www. supercrifical ru)

- Собственная научно-исследовательская базо

- Издание научно-практического журнала -Сверхкритические флюиды: теория и практика: (mww.sct-tp,ru) 
- На поверхностях и в приповерхностных слоях материалов, контактировавших с окислителем, обнаружены нитраты и нитриты.

- Глубина коррозионного поражения поверхностей конструкционных материалов не превышает 50 мкм.

- Исследование конструкционных материалов методами МАЛДИ /ПАЛДИ позволяет визуализировать изменение морфологии поверхности в результате ее коррозионного поражения.

- Использование масс-спектрометрических методов позволяет определить степень и глубину коррозионного поражения конструкционных материалов, длительное время контактировавших с КРТ, а также оценить влияние вредных факторов на герметичность и прочность изделий и продлить сроки их эксплуатации.

\section{ЛИТЕРАТУРА}

1. Буряк А. К., Пыцкий И.С., Сердюк Т.М., Ульянов А. В. Масс-спектрометрия для исследований коррозии и ингибиторов коррозии // Коррозия: материалы, защита. 2011. № 4. C. 6-12.

2. Буряк А.К., Сердюк Т.М. Физикохимические основы применения массспектрометрии с инициированной матрицей/поверхностью лазерной десорбцией / ионизацией для исследования ингибиторов // Коррозия: материалы, защита. 2010. № 9. С. 38-47.

3. Буряк А.К., Сердюк Т.М., Ульянов А. В. Физико-химические основы применения термодесорбционной масс-спектрометрии для исследования ингибиторов и продуктов коррозии // Коррозия: материалы, защита. 2008. № 2. С. 38-47.

4. Михайлов А. А., Панченко Ю. М., Кузнецов Ю. И., Першин Р. В. Атмосферная коррозия и защита металлов. Тамбов, 2016, 554 с.

5. Avdeev Y. G., Kuznetsov Y.I., Buryak A. K. Inhibition of steel corrosion by unsaturated aldehydes in solutions of mineral acids // Corrosion Science. 2013. Vol. 69. P. 50-60.

6. Буряк А. К., Пыцкий И.С., Сердюк Т. М., Ульянов А. В. Сочетание термодесорбции и инициированной матрицей/поверхностью лазерной десорбции / ионизации при масс-спектрометрическом исследовании поверхности конструкционных материалов // Хімія, фізика та технологія поверхні. 2011. Т. 2. № 3. С. 354-360.

7. Томашев Н.Д. и Чернова Г.П. Теория коррозии и коррозионно-стойкие конструкционные сплавы. Металлургия. М., 1986.

8. Буряк А. К., Сердюк Т.М. Хромато-масс-спектрометрия в ракетнокосмической отрасли // Успехи химии. 2013. Т. 82. № 4. С. 366-392.

9. Библиотека масс-спектров Willey275.

10. Полякова А. А., Хмельницкий Р. А. Масс-спектрометрия в органической химии. Л.: 1972.

11. Вульфсон Н.С., Заикин В.Г., Микая А. И. Масс-спектрометрия органических соединений. М.: Химия. 1976. 384 С.

12. Пыцкий И. С., Буряк А. К. Применение масс-спектрометрии с матричнои поверхностно-активированной лазерной десорбцией / ионизацией для

исследования поверхности материалов АМГ-6 И АД-0 // Физикохимия поверхности и защита материалов. 2011. Т. 47. № 6. С. 630-635.

13. Ярцев С.Д., Пыцкий И.С., Белова А. С., Буряк А. К. Обнаружение нитробензойных кислот и их солей на поверхностях конструкционных материалов методом масс-спектрометрии // Журнал аналитической химии. 2018. Т. 73. № 1. С. 46-51.

14. Пыцкий И.С., Буряк А. К. Масс-спектрометрическое исследование химии поверхности сплавов Ад-0 и АМг-6 методом лазерной десорбции / ионизации // Физикохимия поверхности и защита материалов. 2011. Т. 47. № 1. С. 100-105.

15. Пыцкий И.С., Пашинин А.С., Емельяненко А.М., Буряк А.К. Применение методов анализа углов смачивания и масс-спектрометрии с поверхностно-активированной лазерной десорбцией/ионизацией для исследования состояния поверхности алюминиевых сплавов АМг-6 и Ад-0 // Коллоидный журнал. 2014. Т. 77. № 1. С. 73-78.

\section{REFERENCES}

1. Buryak A. K., Pyckij I. S., Serdyuk T. M., Uleanov A. V. Mass-spectromety for Inverstigation of Corrosion and Inhibitors of Corrosin // Korroziya: materialy, zashchita. 2011. no 4. pp. 6-12.

2. Buryak A.K., Serdyuk T.M. Physico-chemical Basis for the Use of Mass Spectrometry Initiated by the Matrix / Surface Laser Desorption / Ionization for Studies of Inhibitors // Korroziya: materialy, zashchita. 2010. No 9. PP. 38-47.

3. Buryak A.K., Serdyuk T.M., Uleanov A. V. Physico-chemical Bases of Application of Thermodesorption Mass Spectrometry for the Study of 
Inhibitors and Corrosion Products // Korroziya: materialy, zashchita. 2008. No 2. PP. 38-47.

4. Mikhailov A. A., Panchenko J.M., Kuznetsov J.И., Pershin R. V. Atmospheric Corrosion and Protection of Petals. Tambov Publ, 2016, $554 \mathrm{p}$.

5. Avdeev Y.G., Kuznetsov Y. I., Buryak A. K. Inhibition of steel corrosion by unsaturated aldehydes in solutions of mineral acids // Corrosion Science. 2013. Vol. 69. P. 50-60.

6. Buryak A. K., Pyckij I.S., Serdyuk T.M., Uleanov A.V. The Combination of Thermal Desorption and Initiated by the Matrix/Surface-assisted Laser Desorption / Ionization Mass Spectrometric Study of the Surface of Structural Materials // Khimia, phisica ta tehnologia poverhnosti. 2011. T. 2. No 3 . PP. 354-360.

7. Tomashov N.D., Chernova G.P. Corrosion Theory and Corrosion Resistant Structural Alloys. Moscow, Metallurgija Publ, 1986.

8. Buryak A. K., Serdyuk T. M. Gas Chromatography-Mass Spectrometry in Rocket-Space Industry // Uspehi khimii 2013. T. 82. No. 4. PP. 366-392.

9. Library of Mass-spectrum Willey275.

10. Poliakova A. A., Khmelnitsky R. A. Mass-spectrometry in Organic Chemistry Leningrad, Khimia Publ. 1972.
11. Wulfson N.S., Zaikin V.G., Mikaia A. I. Mass-spectrometry of Organic Compounds. Moscow, Khimia Publ. 1976, 384 p.

12. Pyckij I.S., Buryak A. K. Application of Mass Spectrometry with Matrixand Surface-Activated Laser Desorption / Ionization to Study the Surface of AMG-6 and AD-0 Materials // Phisicokhimia Poverhnosty i Zaschita Materialov - Protection of Metals and Physical Chemistry of Surfaces. 2011. T. 47. No 6. PP. 630-635.

13. Jartcev S. D., Pyckij I. S., Belova A. S., Buryak A. K. Detection of Nitrobenzoic Acids and their Salts on the Surfaces of Structural Materials by Mass Spectrometry // Jurnal Analiticheskoi Khimii - Journal of Analitical Chemistry. 2018. T. 73. No 1. PP. 46-51.

14. Pyckij I.S., Buryak A. K. Mass Spectrometric Study of Surface Chemistry of AD-0 and AMG-6 Alloys by Laser Desorption / Ionization // Phisicokhimia Poverhnosty i Zaschita Materialov - Protection of Metals and Physical Chemistry of Surfaces. 2011. T. 47. No 6. PP. 100-105.

15. Pyckij I.S., Pashinin A.S., Emelianenko A. M., Buryak A. K. Application of methods for analysis of wetting angles and mass spectrometry with surface-activated laser desorption / ionization to study the surface state of aluminum alloys AMG-6 and Ad-0. Kollodnij jurnal - Colloid Journal. 2014. T. 77. No 1. PP. 73-78.

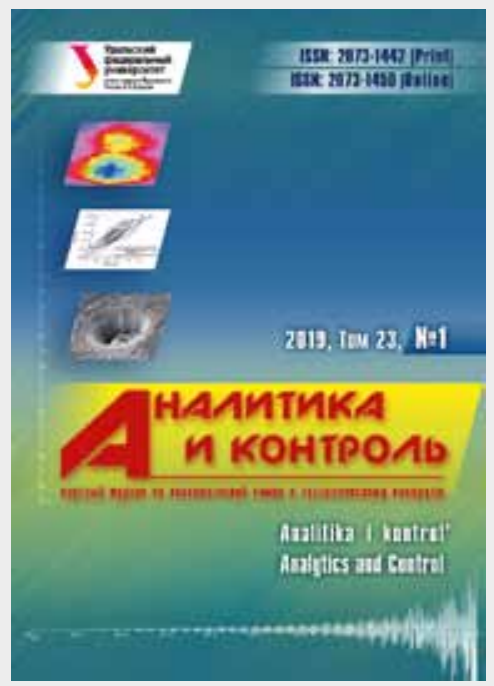

Вышел в свет очередной номер журнала "Аналитика и контроль" 2019, т. 23, № 1

Ревенко А. Г., Шарыкина Д.С.

Применение рентгенофлуоресцентного анализа для исследования химического состава чая и кофе

Пелипасов О. В., Лабусов В.А., Путьмаков А. Н., Чернов К. Н., Боровиков В. М., Бурумов И.Д., Селюнин Д. О., Гаранин В.Г., Зарубин И. А. Спектрометр с микроволновой плазмой «ГРАНДСВЧ» для атомно-эмиссионного анализа

Дзюба А.А., Лабусов В.А., Бабин С.А. Анализаторы МАЭС с линейками фотодетекторов БЛПП-2000 и БЛПП-4000 в сцинтилляционной атомно-эмиссионной спектрометрии
Силькис Э.Г.

Сдвиг спектральных линий некоторых элементов в излучении плазмы источников возбуждения атомно-эмиссионных спектрометров

Абакумов А. Г., Титаренко В. О., Халафян А.А., Темердашев 3.А., Каунова А.А.

Установление сортовой принадлежности винограда по выявленным элементам-маркерам в ягоде и различных ее составляющих частях

Стешин М. О., Потапов А. М., Буланов А.Д., Белозеров Ю. С., Сучков А. И.

Элементный анализ пентакарбонила железа методом масс-спектрометрии с индуктивно связанной плазмой

Китов Б.И.

Способ контроля содержания алмазов в пробе

Байгильдиева Д. И., Байгильдиев Т. М., Шпигун О.А., Родин И.А.

Сравнение кинетики различных вариантов искус ственного старения рукописных штрихов методом высокоэффективной жидкостной хроматографии с масс-спектрометрическим детектированием

Созин А. Ю., Чурбанов М.Ф., Чернова О.Ю., Сорочкина Т. Г., Снопатин Г.Е., Скрипачев И. В., Лесина Ю.А

Идентификация примесей в селене особой чистоты с использованием метода хромато-массспектрометрии
Дейнека В. И., Кульченко Я. Ю., Сидоров А. Н., Блинова И.П., Варушкина С. М., Дейнека Л.А., Ань Тхи Нгок Ву Определение видового состава антоцианов цветков Catharanthus

Зенкевич И. Г., Лелеев Е.

Компенсация эффектов дискриминации при дозировании проб в капиллярные колонки с делением потока

Као Ньят Линь, Дуванова О. В., Зяблов А. Н. Применение полимера с молекулярными отпечатками на основе полиимида в качестве селективного покрытия пьезосенсора для определения олеиновой кислоты в маслах

Рудаков О. Б., Саранов И.А., Полянский К. К. Контроль содержания пальмового масла в смесях с молочным жиром методом ДСК

Крылов В.А., Мосягин П. В., Смирнова Л. В., Буланова С.А., Житухина И.А.,

Пушкарев Г.В.

Повышение чистоты органических растворителей для микроэкстракционного концентрирования примесей

Цюпко Т. Г., Бриленок Н. С., Гущаева К. С., Вершинин В.И.

Определение суммарного содержания фенольных антиоксидантов в чае с применением разных вариантов метода FRAP 